\title{
TRACKING WORKPIECE STABILITY UNDER VARYING CUTTER POSITIONS, MASS AND COMPLIANCE OF WORKPIECE IN POCKET MILLING
}

\author{
Jamdar S.B ${ }^{1}$, Yadav M. H., Mohite S. S. ${ }^{2}$ \\ ${ }^{1,2}$ Department of Mechanical Engineering, Govt. College of Engineering, Karad, 415124, M. S. India \\ seemaj.04@gmail.com
}

\begin{abstract}
Manufacturing accuracy and surface finish as well as productivity by way of high metal removal rates are mainly restricted by the occurrence of workpiece vibrations and loss of stability. In this paper, dynamic stability of Al-6061-T6 prismatic workpiece located in a milling fixture with 3-2-1 location principle and two hydraulically operated clamps is investigated under spatially varying cutter position and continuously decreasing mass and compliance of a workpiece during pocket milling operation. The mathematical model for the fixture- workpiece system is based on Hertzian contact theory. The workpiece and fixture elements are considered rigid and the model takes into account the only contact stiffness. A six-dof dynamical model, that includes metal removal effect (MRE), is developed to simulate the dynamical response of the fixture workpiece system in MATLAB Simulink. Finally, the lift-off and macro-slip is calculated and the stability is determined for each contact. The effect of metal removal on the workpiece during machining is considered for $20 \%$ and $50 \%$ metal removal. For increased metal removal the measured and simulated accelerations are compared and found to have a good agreement with each other. The theoretical model thus developed for dynamic response simulation will be integrated with a Computer Aided Fixture Design (CAFD) system.
\end{abstract}

Keywords: Dynamic Stability, Lift-Off, Macro-Slip, Hertzian Contact Theory, Fixture, Metal Removal Effect

\section{INTRODUCTION}

The primary objective for modeling of machining processes is to develop a predictive capability for machining performance. This is essential to plan efficiently the machining operations that lead to optimal performance, quality and cost. Accurate prediction of the machining force and amplitude of vibration in machining processes is an important concern for industries. Such information, can lead to selection of proper machining parameters, optimal fixture design and avoidance of tool failure. The accurate prediction of the dynamic cutting forces is necessary for stability of the machining process Fixtures are essential elements of the machining process. They are required from manufacturing to assembly operations. The most important criteria for work holding are positioning accuracy, workpiece stability, minimum workpiece displacement and the non-interference with the cutting tool.

During machining, workpiece experiences motion due to cutting and clamping forces.

This affects the location accuracy and final part quality to the considerable extent. In the past, many researchers have taken efforts to predict the dynamic behavior of workpiece subjected to dynamic motion. There are several parameters that influence the forces acting on the cutter. Because of these parameters, the forces may become unpredictable and result in larger dimensional variations when products are produced (Wen-Hsiang Lai 2000). The workpiece motion is restricted through proper location with respect to suitable datum and clamping the workpiece against it (Li, Melkote et al 2001). The factors that affect the fixture- workpiece interface are geometry at contact, stiffness of workpiece and fixture element, contact stiffness and machining parameters. Understanding the effect of these variables on contact forces under dynamic conditions is needed (Hurtado et al. 2002).

The layout of fixture including clamp and locator layout play important role in fixture performance. The optimized locator layout is based on the workpiece repeatability and location accuracy. The clamp layout optimization offers a method to minimize the magnitude of the clamping force (Wang et al. 2005). The mathematical models based on Hertzian contact theory used for simulation of fixtureworkpiece dynamics and analysis of fixturing dynamic stability, are experimentally validated. Sensitivity analysis and effect of minimum clamping force on the dynamic stability during machining is presented (Deng 2006). A Genetic Algorithm (GA) based optimization method is proposed to arrive at a layout of error containing locators for minimum machining error satisfying the tolerance requirements and providing deterministic location. This may be advantageous in cases where a less strict tolerance on locator is acceptable thus reducing the cost of manufacture of locators (Vishnupriyan et al. 2010)

\section{Mathematical Model}

Mathematical procedure for modelling and analysis of dynamic behavior of fixture -workpiece system is represented by mathematical model. This model is based on 
Hertzian contact theory and takes into account the effect of metal removal. Following are a few assumptions made while formulating this model

- Fixture and workpiece are considered rigid and therefore, the contact stiffness at the fixture - workpiece contact is considered.

- It is assumed that the contact stiffness is clamping force dependent and independent of machining force.

- The clamping force remains constant during machining.

- The mass of the fixture element is negligible as compared to the mass of the workpiece.

- Damping is not considered in the dynamic model.

As shown in figure 1, a prismatic workpiece of Al 6061-T-6 $(100 \mathrm{~mm} \times 100 \mathrm{~mm} \times 70 \mathrm{~mm})$ is located in $3-2-1$ fixture. The material properties of $\mathrm{Al}$ 6061-T6 workpiece and fixture elements are given in the following table.

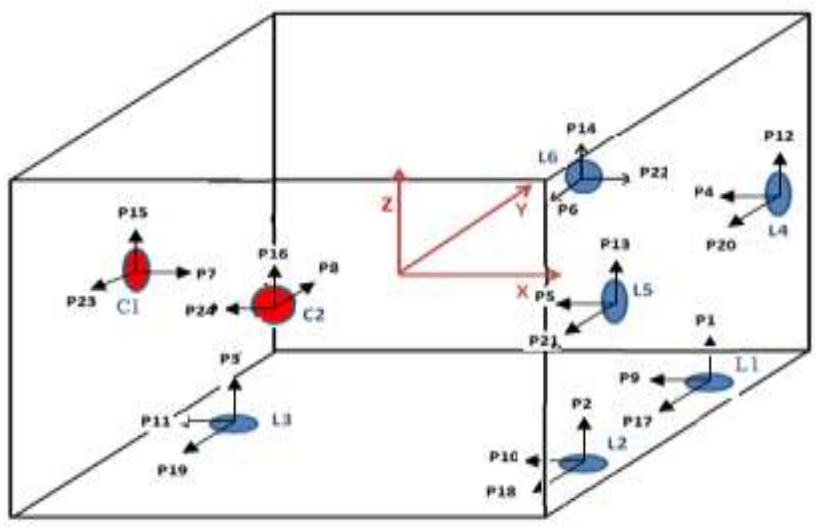

Figure 1: Fixture-Workpiece system with local contact forces

Table 1: Properties of workpiece and fixture element

\begin{tabular}{|c|c|c|c|}
\hline $\begin{array}{l}\text { Sr. } \\
\text { No. }\end{array}$ & Parameter & Workpiece & $\begin{array}{l}\text { Spherical } \\
\text { Locator }\end{array}$ \\
\hline 1 & Material & Al-6061-T6 & Hardened steel \\
\hline 2 & $\begin{array}{l}\text { Dimensions } \\
(\mathrm{mm})\end{array}$ & $100 \times 100 \times 70$ & $\begin{array}{ll}\text { Spherical } & \text { tipped } \\
\text { having } & \text { radius } \\
19.81 \mathrm{~mm} & \end{array}$ \\
\hline 3 & $\begin{array}{l}\text { Young's } \\
\text { modulus E } \\
(\mathrm{GPa})\end{array}$ & 70 & 200 \\
\hline 4 & $\begin{array}{l}\text { Poisson's } \\
\text { ratio }\end{array}$ & 0.33 & 0.285 \\
\hline 5 & $\begin{array}{l}\text { Yield } \\
\text { strength (Sy) } \\
(\mathrm{MPa})\end{array}$ & 270 & $(300-400)$ \\
\hline 6 & $\begin{array}{l}\text { Shear } \\
\text { modulus } \\
(\mathrm{GPa})\end{array}$ & 26.31 & 77.82 \\
\hline 7 & $\begin{array}{l}\text { Density } \\
(\mathrm{Kg} / \mathrm{m} 3)\end{array}$ & 2700 & 7800 \\
\hline 8 & Weight (Kg) & 1.89 & $\begin{array}{l}6 \text { locator, } 2 \\
\text { clamps }\end{array}$ \\
\hline 9 & $\begin{array}{l}\text { Static } \\
\text { coefficient of } \\
\text { friction }\end{array}$ & 0.375 & - \\
\hline
\end{tabular}

The fixture element layout is as shown below

Table 2: Layout of fixture element

\begin{tabular}{|l|l|l|l|}
\hline $\begin{array}{l}\text { Fixture } \\
\text { Element }\end{array}$ & $\mathrm{Xg}(\mathrm{mm})$ & $\mathrm{Yg}(\mathrm{mm})$ & $\mathrm{Zg}(\mathrm{mm})$ \\
\hline L1 & 45 & 45 & -35 \\
\hline L2 & 45 & -45 & -35 \\
\hline L3 & -45 & 1 & -35 \\
\hline L4 & 50 & 40 & 1 \\
\hline L5 & 50 & -40 & 1 \\
\hline L6 & 1 & 50 & 1 \\
\hline C1 & -50 & 1 & 1 \\
\hline C2 & 1 & -50 & 1 \\
\hline
\end{tabular}

\section{Static Model}

The workpiece remains in static equilibrium under the action of clamps and its weight. The elastic deformation of the workpiece at a fixture-workpiece contact due to clamping, the contact reaction force must be known. The principle of minimum total complementary energy is applied to develop a model that gives the reaction force at each fixture-workpiece contact. The complementary energy of fixture-workpiece contacts can be computed from the contact force-displacement relationships, as given in the contact mechanics literature. For a spherical-tipped fixture element pressed against a curved workpiece surface, the relationship is given by eq. 1 and 2 ,

$\delta_{z}=\left(\frac{9 P_{i}{ }^{2}}{16 R E^{* 2}}\right)^{\frac{1}{3}}$

$\delta_{j}=\frac{Q_{j}}{8 a}\left(\frac{2-v_{w}}{G_{w}}+\frac{2-v_{f}}{G_{f}}\right)$ For $\mathrm{j}=\mathrm{x}$ or $\mathrm{y}$

where, $P_{i}$ and $\delta_{z}$ represent normal force and normal deformation. $Q_{j}$ And $\delta_{j}$ represent tangential force and tangential deformation.

$a$ - Contact region radius,

$a=\left(\frac{3 P_{i}}{4 E^{*}}\right)^{\frac{1}{3}}$

$R$ - Relative curvature at contact $\left(\frac{1}{R}=\frac{1}{R_{w}}+\frac{1}{R_{f}}\right)$ with $R_{w}$ is the local radius of the workpiece and $R_{f}$ is the radius of the spherical tip.

$E^{*}=\left[\left(\frac{1-v_{w}^{2}}{E_{w}}\right)+\left(\frac{1-v_{f}^{2}}{E_{f}}\right)\right]^{-1}$

The total complementary energy for all $(\mathrm{L}+\mathrm{C})$ contact is written as

$\Pi_{c}=\sum_{i=0}^{L+C} \int_{0}^{P_{i}} \delta_{i z c} d P_{i}+\int_{0}^{Q_{i x}} \delta_{i x c} d Q_{i x}+\int_{0}^{Q_{i y}} \delta_{i y c} d Q_{i y}$

To find the reaction forces complementary energy equation is minimized under the constraints. Hence, the objective function is minimization of the total complementary energy at contact.

Therefore, the quasi-static model is obtained by combining Equations (5) to (6) and is summarized as 
$\min \pi_{c}\left(P_{i}, Q_{i x}, Q_{i y}\right)$

Subjected to:

Linear constraint and nonlinear constraint

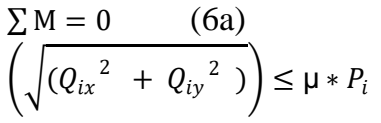

$$
\sum F=0
$$

$P_{i} \geq 0(i=1,2 \ldots \ldots \mathrm{L}+\mathrm{C})$

$P_{i} \leq S_{y} A_{i}$

$P_{j}=F_{c j}(j=1,2 \ldots . . \mathrm{C}+1)$

Solving equation (6) yields the contact reaction forces, $P_{i} Q_{i x}$ and $Q_{i y}$ with $i=1$ to $(\mathrm{L}+\mathrm{C})$.

The fixture-workpiece contact stiffness, $\left(k_{i j c}\right.$ from Equation (7) can be obtained by differentiating equation (1) and is given by,

Normal contact stiffness $K_{i z}$ is

$K_{i z}=\frac{\partial P}{\partial \delta z}=\frac{3}{2}\left(\frac{16 * R * E^{* 2}}{9}\right) * P_{i}^{\frac{1}{3}}$

Tangential contact stiffness is

$K_{i x}=K_{i y}=\frac{\partial Q j}{\partial \delta j}=8 a\left[\left(\frac{2-v_{w}}{G_{w}}\right)+\left(\frac{2-v_{f}}{G_{f}}\right)\right]^{-1}$

The normal and tangential contact stiffness is normal force dependent. The static model, given by equation (6), can be solved using standard nonlinear program solvers. Its solution, i.e., the reaction forces at the fixture-workpiece contacts due to clamping, and machining forces, is then substituted into equation (7), to compute the normal and tangential contact stiffness $\left(K_{i x}, K_{i y}, K_{i z}, \ldots, K_{(L+C) z}\right)$.

Dynamic Model

A second order differential equation that governs the vibratory motion of the fixtured workpiece during machining is obtained as shown by equation (8)

$[\mathrm{M}] \ddot{\overline{\mathrm{q}}}+[\dot{\mathrm{M}}] \dot{\overline{\mathrm{q}}}+[\mathrm{K}] \overline{\mathrm{q}}=\overline{\mathrm{Q}}(\mathrm{t})(8)$

$\bar{Q}(t)$ represents the cutting forces applied to the system and is given by,

$\overline{\mathrm{Q}}(\mathrm{t})=\left\{\begin{array}{c}\overline{\mathrm{F}}(\mathrm{t}) \\ \bar{\Gamma}(\mathrm{t})+\overline{\mathrm{r}}_{\mathrm{m}}(\mathrm{t}) \times \overline{\mathrm{F}}(\mathrm{t})\end{array}\right\} \in \mathrm{R}^{6}(9)$

Where, $\overline{\mathrm{F}}(\mathrm{t})$ and $\bar{\Gamma}(\mathrm{t})$ represent the machining force and torque vectors, respectively. And $\bar{r}_{m}(t)$ is the position vector from the centre of gravity (C.G.) of the workpiece to the machining point $\mathrm{M}$.

Figure 2 shows the end milling operation on prismatic component with 3-2-1 location. The workpiece coordinate system is shown.

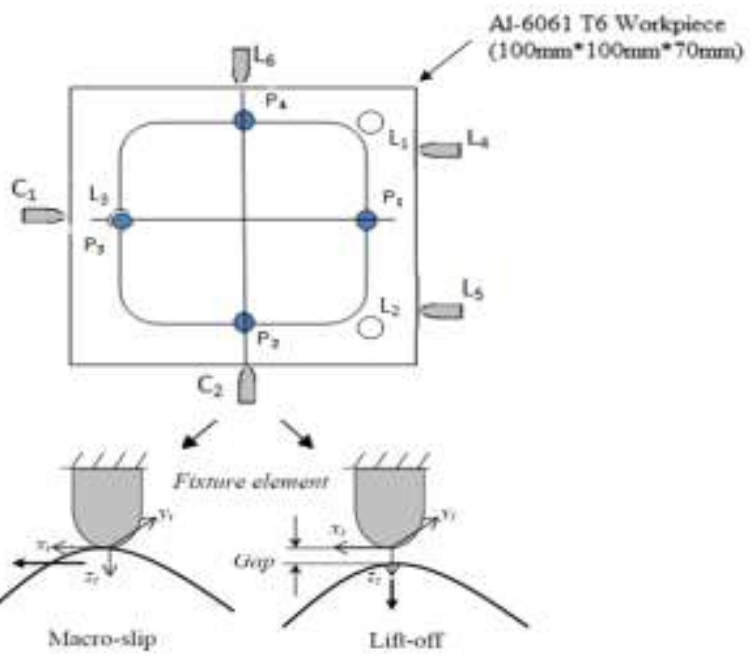

Figure 2: Stability Criteria i) Macro-slip ii) Lift-off [Deng 2006]

In the contact coordinate system $\left(\mathrm{x}_{\mathrm{i}} \mathrm{y}_{\mathrm{i}} \mathrm{z}_{\mathrm{i}}\right.$ in Figure 2), lift-off is a positive displacement of the workpiece in the $z_{i}$ direction, and macro-slip occurs when the resultant friction force in the $x_{i} y_{i}$ plane exceeds a limit of the normal force in the $z_{i}$ direction and the static coefficient of friction at the contact.

Therefore, the criteria for fixturing dynamic stability can be written as follows:

$\operatorname{Max}\left\{\Delta_{\text {iz }}(\mathrm{t})\right\} \leq 0$

$\operatorname{Max}\left\{\sqrt{\left[\mathrm{k}_{\mathrm{ix}} \Delta_{\mathrm{ix}}(\mathrm{t})\right]^{2}+\left[\mathrm{k}_{\mathrm{iy}} \Delta_{\text {iy }}(\mathrm{t})\right]^{2}}-\mu_{\mathrm{S}}^{\mathrm{i}}\left[\mathrm{k}_{\mathrm{iz}}\left|\Delta_{\mathrm{iz}}(\mathrm{t})\right|\right]\right\} \leq 0$

Where, $\mathrm{t}$ is the machining time; $\Delta_{\text {ix }}(\mathrm{t}), \Delta_{\mathrm{iy}}(\mathrm{t})$ and $\Delta_{\mathrm{iz}}(\mathrm{t})$ are the superposed displacements of the workpiece at the ith fixture-workpiece contact in the $\mathrm{x}_{\mathrm{i}}, \mathrm{y}_{\mathrm{i}}$ and $\mathrm{z}_{\mathrm{i}}$ directions, respectively; $\mathrm{i}=1$ to $(\mathrm{L}+\mathrm{C})$; $\mu_{\mathrm{S}}^{\mathrm{i}}$ is the static coefficient of friction at the ith contact; $\mathrm{k}_{\mathrm{ix}}, \mathrm{k}_{\mathrm{iy}}$ and $\mathrm{k}_{\mathrm{iz}}$ are the local composite stiffnesses in the $\mathrm{x}_{\mathrm{i}}, \mathrm{y}_{\mathrm{i}}$ and $\mathrm{z}_{\mathrm{i}}$ directions respectively [Deng 2006].

The total displacement of workpiece at the ith fixtureworkpiece contact due to the combined effects of clamping and machining is given by:

$\Delta_{\mathrm{ij}}=\operatorname{dij}(\mathrm{t})-\delta_{\mathrm{ij}}$ For $\mathrm{j}=\mathrm{x}$ or $\mathrm{y}$

where symbols $\mathrm{d}$ and $\delta$ represent the dynamic and static displacements, respectively. The dynamic model explained in Eq. (8) is solved with the help of Simulink. The ode23 solver is used to explore the dynamic behavior of fixture workpiece system. The input required by the dynamic model is inertia matrix $[\mathrm{M}]$, rate of 


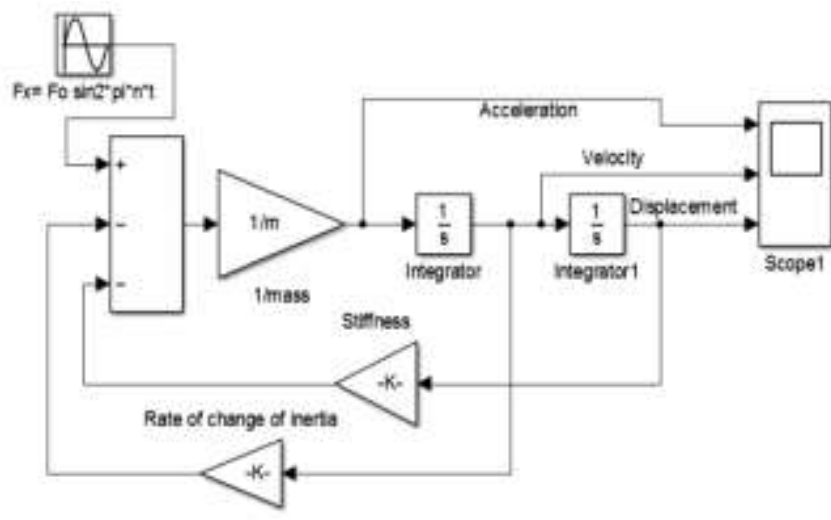

FIGURE 3: DYNAMIC MODEL FOR CALCULATING ACCELERATION, VELOCITY AND DISPLACEMENT IN X DIRECTION

change of inertia matrix $[\dot{\mathrm{M}}]$, Force and moment matrix and system contact stiffness Matrix [K] obtained from contact stiffness module. The simulink model for solving the dynamic model in $\mathrm{X}$ direction is shown in figure 3 . The output of the Simulink model is displayed in the scope block. After simulating the system represented by the model the outputs obtained is displacement, velocity and acceleration shown in figure 4 . There are six models for six equations resulting into six degrees of freedom of workpiece.

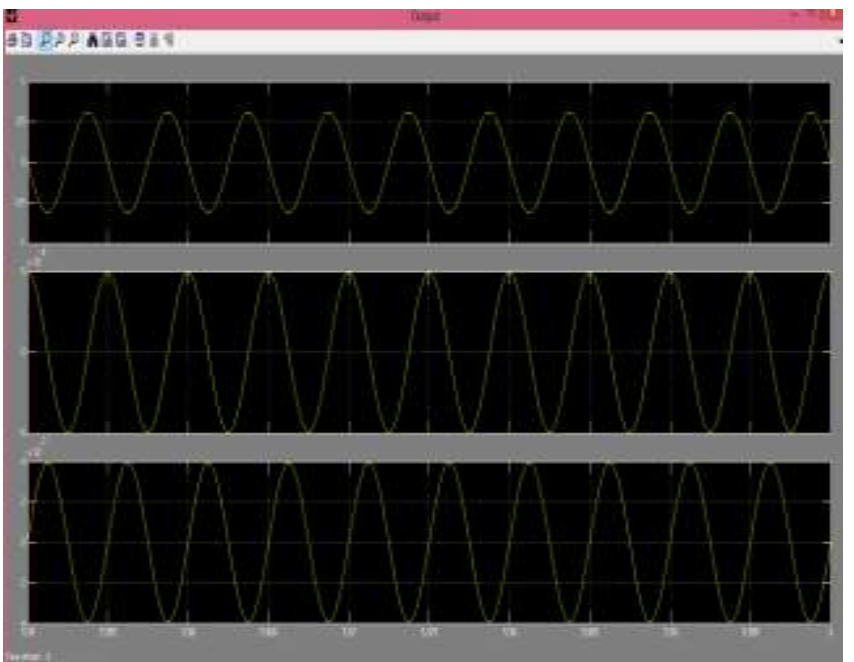

Figure 4: Output of the Simulink model showing displacement, velocity and acceleration

\section{Experimental Set up}

A 3-2-1 fixture containing the Aluminium-6061-T6 workpiece clamped with two hydraulically operated clamps, is mounted on dynamometer with stud mounting. The dynamometer (Kistler 9272) and a tri-axial accelerometer (SKF 4370) are used to measure the dynamic cutting forces and accelerations of the workpiece in $\mathrm{X}, \mathrm{Y}$ and $\mathrm{Z}$ directions. The data is collected using SKF Microlog Analyser (CMXA 45). A pocket milling operation is performed on $\mathrm{Al} 6061$ workpiece size $100 \mathrm{~mm} \times 100 \mathrm{~mm} \times 70 \mathrm{~mm}$, with HSS end mill cutter $\varnothing 25 \mathrm{~mm}$ diameter, 4 flute and $30^{\circ}$. Following are the cutting parameters used during machining. See figure 6.
Table 3: Cutting parameters HSS end mill cutter $\varnothing 25 \mathrm{~mm}$ diameter, 4 flute and 300 helix angle

\begin{tabular}{|l|l|}
\hline $\begin{array}{l}\text { Axial Depth of } \\
\text { cut }\end{array}$ & $0.5 \mathrm{~mm}$ \\
\hline $\begin{array}{l}\text { Radial Depth } \\
\text { of cut }\end{array}$ & $12.5 \mathrm{~mm}$ \\
\hline $\begin{array}{l}\text { Cutting } \\
\text { Velocity }\end{array}$ & $199 \mathrm{~m} / \mathrm{min}$ \\
\hline Feed rate & $0.12 \mathrm{~mm} / \mathrm{rev}$ \\
\hline Pocket size & $77 \mathrm{~mm} \times 77 \mathrm{~mm} \times 58 \mathrm{~mm}$ \\
\hline
\end{tabular}

Experiments were performed on Compact Mill of MTAB Engineers, Chennai with Siemens controller. Milling Tool Dynamometer was mounted on the machine bed as shown in figure 5 and fixture containing workpiece was mounted on the dynamometer. The clamping force of $2000 \mathrm{~N}$ was kept constant throughout the pocket milling process. The machining was performed by $\varnothing 25 \mathrm{~mm}, 4$ flute HSS end mill cutter with $30^{\circ}$ helix angle. The cutting forces were measured by Kistler 9272 dynamometer. Tri-axial accelerometer mounted on the workpiece measure accelerations in three directions $\mathrm{X}, \mathrm{Y}$ and $\mathrm{Z}$ of the fixture workpiece system.

The acceleration data was acquired through SKF Microlog Analyser. The experiments were performed for pocket size $77 \mathrm{~mm} \times 77 \mathrm{~mm} \times 58 \mathrm{~mm}$ for $50 \%$ metal removal. The force and acceleration data was acquired on the straight edges of outer periphery of the pocket at different depth levels with an increment of $10 \mathrm{~mm}$. Dynamic simulations are carried out for all points.

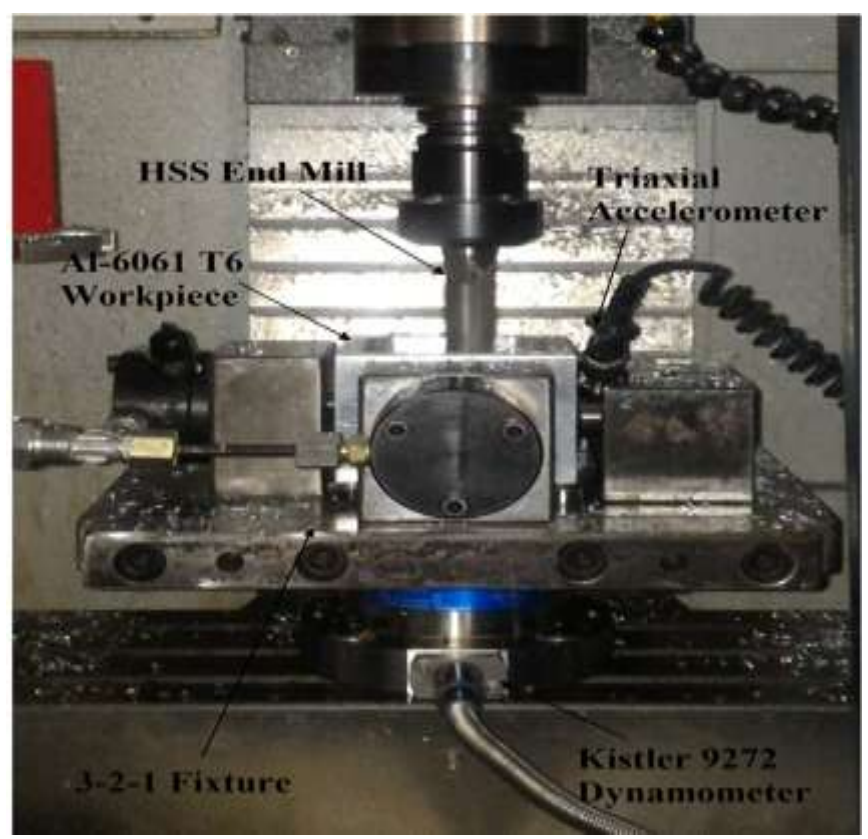

Figure 5: Experimental set up for analysis of dynamic behavior of fixture-workpiece

\section{RESULTS AND DISCUSSION}

This section presents the results obtained from mathematical model and experimentation. The experiments were performed for rectangular pocket $(77 \mathrm{~mm} \times 77 \mathrm{~mm} \times 58 \mathrm{~mm})$ 
milling operation till $50 \%$ metal is removed. Cutting forces and acceleration data is acquired on the straight edges on the pocket periphery along $\mathrm{X}$ and a $\mathrm{Y}$ direction for every pass with an increment of $10 \mathrm{~mm}$ depth till about $58 \mathrm{~mm}$ is reached. The experimental results are divided into three sections as follows.

Variation of the Cutting Forces With \% Metal Removal

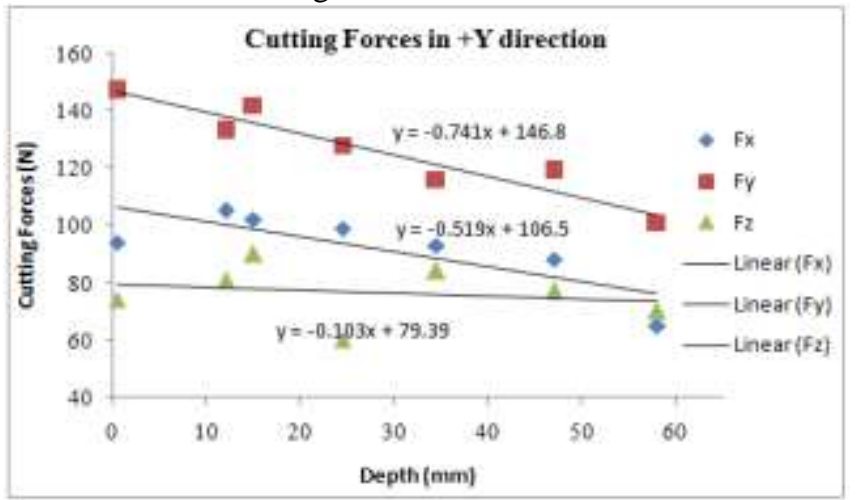

Figure 6: Variation of the cutting forces $\mathrm{F}_{\mathrm{x}}, \mathrm{F}_{\mathrm{y}}$ and $\mathrm{F}_{\mathrm{z}}$ with $\%$ metal removal in $+\mathrm{Y}$ direction

The experimentally measured cutting forces $F_{x}, F_{y}$ and $F_{z}$ are measured in $\pm \mathrm{X}$ and $\pm \mathrm{Y}$ directions on the periphery of the rectangular pocket. The forces obtained in $+X$ and $-X$ directions show almost same magnitudes with change in the directions with each other. Same is true for $+\mathrm{Y}$ and $-\mathrm{Y}$ directions. Figure 6 shows the variation of cutting force amplitudes of $\mathrm{F}_{\mathrm{x}}, \mathrm{F}_{\mathrm{y}}$ and $\mathrm{F}_{\mathrm{z}}$ with $\%$ metal removal in $+\mathrm{Y}$ direction. The force amplitudes in $-\mathrm{Y}$ shows the similar nature of cutting forces. Figure 7 shows the variation of the cutting forces $\mathrm{F}_{\mathrm{x}}, \mathrm{F}_{\mathrm{y}}$ and $\mathrm{F}_{\mathrm{z}}$ with $\%$ metal removal in $-\mathrm{X}$ direction. The $+\mathrm{X}$ direction shows the similar nature of cutting forces.

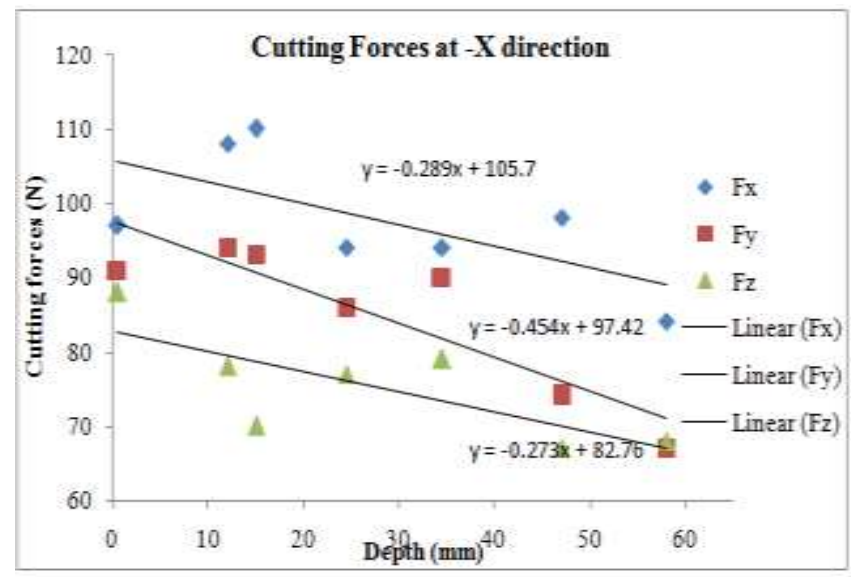

Figure 7: Variation of the cutting forces $F_{x}, F_{y}$ and $F_{z}$ with $\%$ metal removal $-\mathrm{X}$ direction

Variation of the Translational Accelerations With \% Metal Removal

The acceleration values $a_{x}, a_{y}$ and $a_{z}$ are measured in $\pm X$ and $\pm Y$ directions on the periphery of the rectangular pocket. The measured accelerations are integrated to obtain the displacements. The acceleration graphs are shown below.

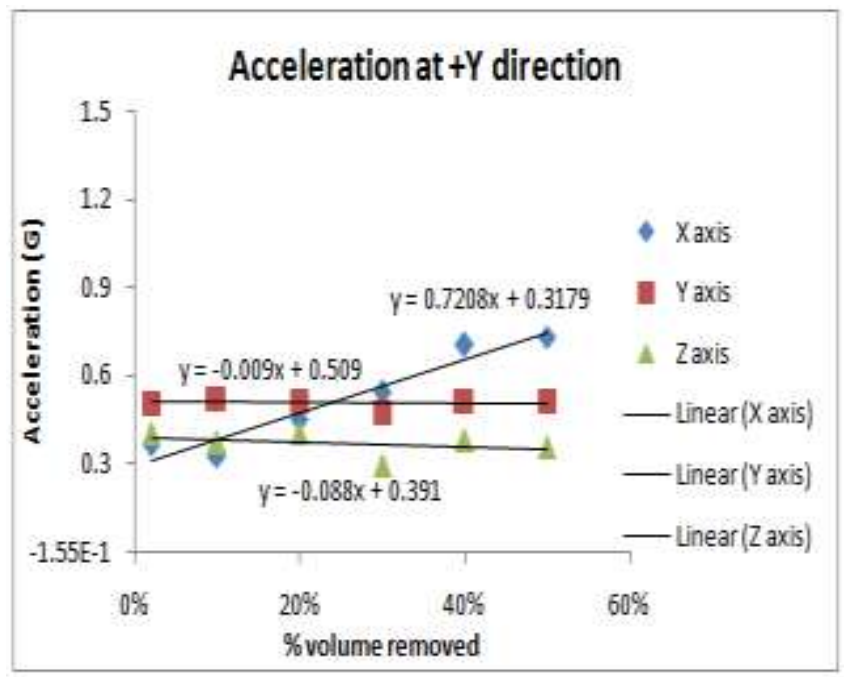

Figure 8: Variation of Translational accelerations $\mathrm{a}_{\mathrm{x}}, \mathrm{a}_{\mathrm{y}}$, and $\mathrm{a}_{\mathrm{z}}$ with $\%$ metal removal in $+\mathrm{Y}$ direction.

That means the acceleration for $+\mathrm{Y}$ and $-\mathrm{Y}$ show similar nature whereas the acceleration $\mathrm{t}$ for $-\mathrm{X}$ and $+\mathrm{X}$ show resemblance with each other for at various depth levels. See figure 8 and 9 . Table 4 shows that as compared to initial accelerations, the rise of $23 \%$ and $1 \%$ in translational acceleration for $20 \%$ and $50 \%$ metal removal in $+Y$ and $-X$ directions respectively. For $\mathrm{Z}$ axis there is no change in the accelerations for $20 \%$ metal removal and further drops to $11 \%$ for $50 \%$ metal removal in $+\mathrm{Y}$ direction as compared to initial acceleration.

Table 5 shows that as compared to accelerations the rise of $28 \%, 14.08 \%$ in translational acceleration for $20 \%$ metal removal and further rise to $68 \%$ and $7 \%$ for $50 \%$ metal removal in $+Y$ and $-\mathrm{X}$ directions respectively. The acceleration drops to- $16 \%$ to $-18 \%$ for $20 \%$ and $50 \%$ metal removal in $\mathrm{Z}$ direction.

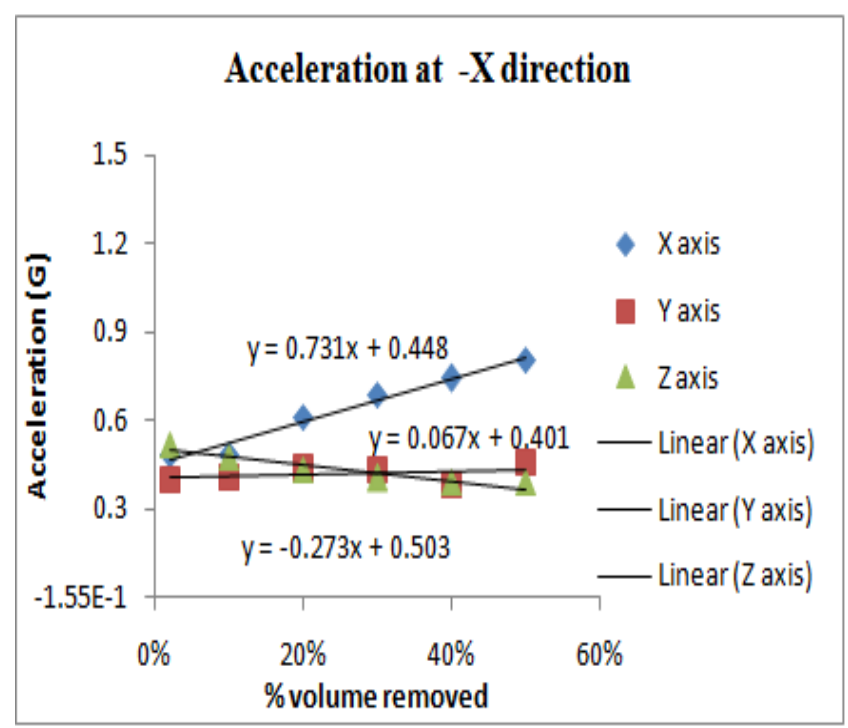

Figure 9: Variation of Translational accelerations $a_{x}, a_{y}$, and $\mathrm{a}_{\mathrm{z}}$ with $\%$ metal removal in $-\mathrm{X}$ direction. 
Table 4: $\%$ variation in accelerations with $\%$ metal removal in $+Y$ direction

\begin{tabular}{|c|c|c|c|c|c|}
\hline \multirow{2}{*}{$\begin{array}{l}\text { Accelera } \\
\text { tion }\end{array}$} & \multicolumn{3}{|c|}{$\begin{array}{ll}\% & \text { volume } \\
\text { removed } & \end{array}$} & \multirow{2}{*}{$\begin{array}{l}\% \text { rise } \\
\text { from } \\
0 \%-20 \%\end{array}$} & \multirow{2}{*}{$\begin{array}{l}\% \text { rise } \\
\text { from } \\
20 \%- \\
50 \%\end{array}$} \\
\hline & $2 \%$ & $20 \%$ & $\begin{array}{l}50 \\
\%\end{array}$ & & \\
\hline$a_{x 1}(\mu m)$ & $\begin{array}{l}0.3 \\
67 \\
\end{array}$ & $\begin{array}{l}0.45 \\
3 \\
\end{array}$ & $\begin{array}{l}0.6 \\
1 \\
\end{array}$ & $23 \%$ & $66 \%$ \\
\hline $\mathrm{a}_{\mathrm{y} 1}(\mu \mathrm{m})$ & $\begin{array}{l}0.5 \\
08\end{array}$ & $\begin{array}{l}0.51 \\
1 \\
\end{array}$ & $\begin{array}{l}0.5 \\
16 \\
\end{array}$ & $1 \%$ & $2 \%$ \\
\hline $\mathrm{a}_{\mathrm{z} 1}(\mu \mathrm{m})$ & $\begin{array}{l}0.4 \\
03\end{array}$ & $\begin{array}{l}0.37 \\
4\end{array}$ & $\begin{array}{l}0.3 \\
59 \\
\end{array}$ & $0 \%$ & $-11 \%$ \\
\hline
\end{tabular}

Table 5: \% variation in accelerations with $\%$ metal removal in $-\mathrm{X}$ direction

\begin{tabular}{|c|c|c|c|c|c|}
\hline \multirow{2}{*}{$\begin{array}{l}\text { Accelera } \\
\text { tion }\end{array}$} & \multicolumn{3}{|c|}{$\begin{array}{ll}\% & \text { volume } \\
\text { removed } & \end{array}$} & \multirow{2}{*}{$\begin{array}{l}\% \text { rise } \\
\text { from } \\
0 \%- \\
20 \%\end{array}$} & \multirow[b]{2}{*}{$\begin{array}{lll}\% & \text { rise } & \text { from } \\
20 \% & -50 \% & \\
\end{array}$} \\
\hline & $2 \%$ & $\begin{array}{l}20 \\
\%\end{array}$ & $\begin{array}{l}50 \\
\%\end{array}$ & & \\
\hline $\mathrm{a}_{\mathrm{x} 2}(\mu \mathrm{m})$ & $\begin{array}{l}0.4 \\
8 \\
\end{array}$ & $\begin{array}{l}0.6 \\
12 \\
\end{array}$ & $\begin{array}{l}0.8 \\
06\end{array}$ & $28 \%$ & $68 \%$ \\
\hline $\mathrm{a}_{\mathrm{y} 2}(\mu \mathrm{m})$ & $\begin{array}{l}0.3 \\
99 \\
\end{array}$ & $\begin{array}{l}0.4 \\
28\end{array}$ & $\begin{array}{l}0.4 \\
6 \\
\end{array}$ & $7 \%$ & $13 \%$ \\
\hline $\mathrm{a}_{\mathrm{z} 2}(\mu \mathrm{m})$ & $\begin{array}{l}0.5 \\
17\end{array}$ & $\begin{array}{l}0.4 \\
34 \\
\end{array}$ & $\begin{array}{l}0.3 \\
89 \\
\end{array}$ & $-16 \%$ & $-18 \%$ \\
\hline
\end{tabular}

Dynamical Behavior of the Fixture Workpiece System under 2000N Clamping Force

Three translational accelerations are obtained by dynamic model are then twice integrated to obtain translational displacements $\delta_{\mathrm{x}}, \delta_{\mathrm{y}}$ and $\delta_{\mathrm{z}}$. The total displacement is calculated from equation 11. The lift-off and macro-slip are calculated by equation 10 , at $50 \%$ metal removal for all directions, under clamping force of $2000 \mathrm{~N}$ for both the clamps. See figure 10 and 11.

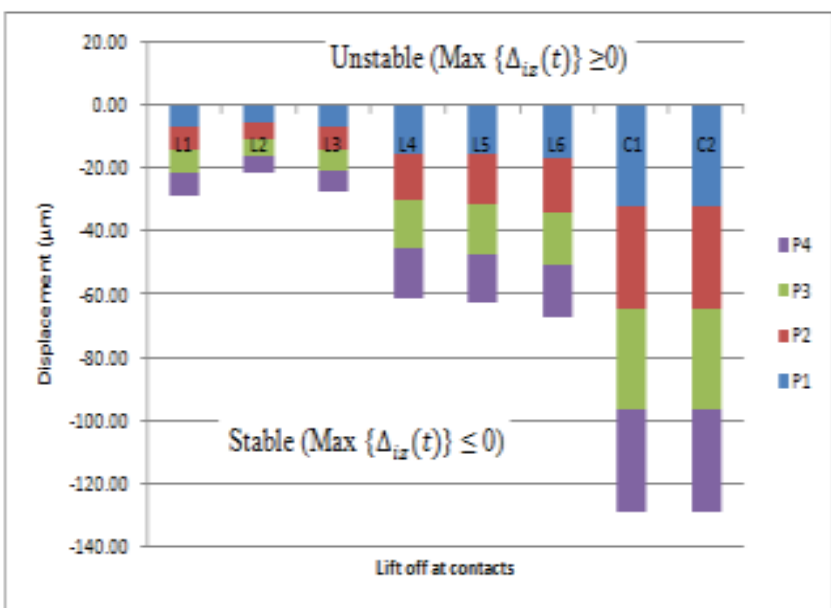

Figure 10: Lift-off in first pass under 2000N clamping force on both the clamps

The measured cutting forces, inertia matrix and rate of change of inertia matrix, system stiffness matrix and change in position of $\mathrm{CG}$ of workpiece were then fed to the dynamic model coded in MATLAB ${ }^{\circledR} 10$ and then solved by using ode23 solver.

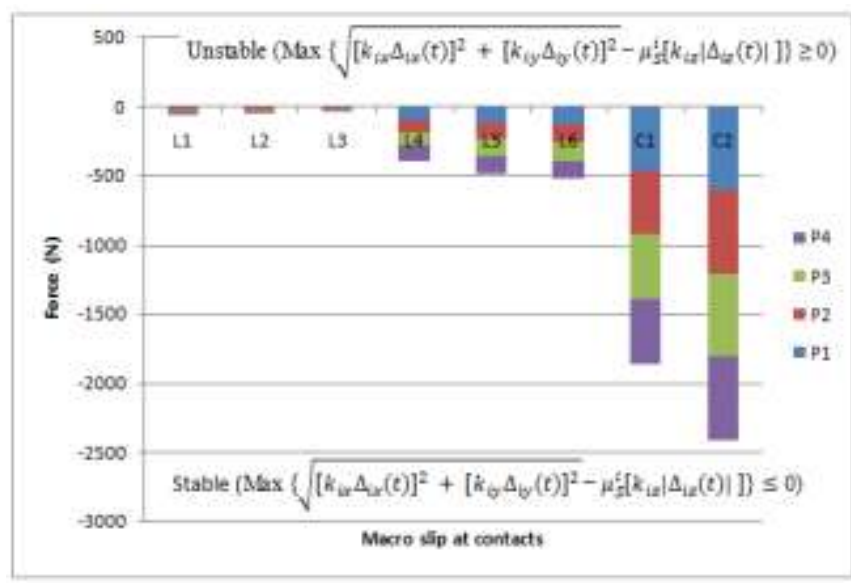

Figure 11: Macro-slip in first pass under 2000N clamping force on both the clamps

Next, conclusions are drawn based on above result and discussions.

\section{CONCLUSIONS}

Throughout the pocket milling operation, the cutting forces and the vibration response of the workpiece were continuously tracked till 50\% metal is removed. The Fx and Fy forces flipped their magnitudes and direction, with change in table feed direction from $\pm x$ to $\pm y$ axis, as expected. With the increase in pocket depth the Fx and Fy were found to decrease steadily at a rate of $50 \%-70 \%$ with pocket depth, this is due to decreasing length (or leverage) of the position vector joining cutting point and the point where forces are sensed/measured. The force $\mathrm{Fz}$ was found to remain fairly constant. The measured workpiece vibration response (acceleration) too is found to follow a similar pattern with depth of pocket milling. Thus, in the early part of the pocket milling the chances of workpiece getting unstable due to macro-slip or lift-off were more and gradually the stability of workpiece increased. This was evident from the calculated reaction forces at the locators using theoretical model developed in this work. The instability of workpiece, in the early part of pocket milling, can be countered by either applying higher clamping forces initially or by using lower feed rate in an adaptive strategy.

\section{REFERENCES}

[1]. Wen-Hsiang Lai (2000) Modeling of Cutting Forces in End Milling Operations Tamkang Journal of Science and Engineering, Vol. 3:15-22

[2]. B. Li and S. N. Melkote et al. (2001), Fixture Clamping Force Optimization and its Impact on Workpiece Location Accuracy, International Journal Adv. Manufacturing Technology 17:104-113.

[3]. Jose F. Hurtado, Shreyes N. Melkote, (2002) Modeling and Analysis of the Effect of Fixture-Workpiece Conformability on Static Stability Journal Of Manufacturing Science And Engineering 124:234-241 
[4]. Y. Wang_, X. Chen, Q. Liu, N. Gindy (2006) Optimization of machining fixture layout under multiconstraints International Journal of Machine Tools \& Manufacture 46:1291-1300

[5]. Haiyan Deng (2006) Analysis and synthesis of fixturing dynamic stability in machining accounting for material removal effect, A Ph. D thesis submitted to the Georgia Institute of Technology Atlanta, Georgia

[6]. S. Vishnupriyan, M. C. Majumder, K. P. Ramachandran (2010) Optimization of machining fixture layout for tolerance requirements under the influence of locating errors, International Journal of Engineering, Science and Technology, 2-1: 152-162 